\title{
The significance of galectin-3 as a new basal cell marker in prostate cancer
}

\author{
Y Wang ${ }^{*, 1,4}$, V Balan ${ }^{1,4}$, X Gao ${ }^{1}$, PG Reddy ${ }^{2}$, D Kho ${ }^{1}$, L Tait ${ }^{3}$ and A Raz ${ }^{*, 1}$
}

Prostate cancer may originate from distinct cell types, resulting in the heterogeneity of this disease. Galectin-3 (Gal-3) and androgen receptor (AR) have been reported to play important roles in the progression of prostate cancer, and their heterogeneous expressions might be associated with different cancer subtypes. Our study found that in various prostate cancer cell lines Gal-3 expression was always opposite to AR expression and other luminal cell markers but consistent with basal cell markers including glutathione $S$-transferase- $\pi$ and Bcl-2. This expression pattern was confirmed in human prostate cancer tissues. Our results also showed that prostate cancer cells positive with basal cell markers were more aggressive. Downregulation of Gal-3 expression resulted in increased apoptotic potential and decreased metastasis potential of prostate cancer cells. Our findings demonstrate for the first time that Gal-3 may serve as a new marker for basal characteristics of prostate cancer epithelium. This study helps us to better understand the heterogeneity of prostate cancer. The clinical significance of this study lies in the application of Gal-3 to distinguish prostate cancer subtypes and improve treatment efficacy with designed personalized therapy.

Cell Death and Disease (2013) 4, e753; doi:10.1038/cddis.2013.277; published online 1 August 2013

Subject Category: Cancer

Prostate cancer is the most common malignant neoplasm and the second most common cause of death from malignancies in men. ${ }^{1}$ Three main epithelial cell types have been identified in prostate epithelium: luminal, basal, and neuroendocrine. The luminal cells are polarized columnar cells and express characteristic markers such as androgen receptor (AR), prostate-specific antigen (PSA), cytokeratin-8 (CK-8), and CK-18. Basal cells, which are beneath the luminal epithelium and lined by the basement membrane, express biomarkers including CK-5, CK-14, p63, Bcl-2, glutathione $S$-transferase- $\pi$ $(\mathrm{GST}-\pi)$, and so on. The neuroendocrine cells are a rare population of cells and sparsely scattered between the luminal and basal layers; they are characterized by the expression of chromogranin A and serotonin. ${ }^{2,3}$ It is possible that there are different prostate cancer cells of origin. Some studies support that luminal cells are the cells of origin of prostate cancer; ${ }^{4-6}$ others demonstrate that prostate cancer arises from cells with basal phenotype. ${ }^{7-9}$ Recently, it has been proposed that prostate cancers arise from prostate cancer stem cells. ${ }^{10,11}$

Galectin-3 (Gal-3), a $\beta$-galactoside-binding protein, has multiple biological functions. It has been demonstrated to play important roles in tumorigenicity and progression through regulating cell proliferation, apoptosis, cell invasion, and metastasis. ${ }^{12-14}$ Besides of the roles in cancer, Gal-3 is also associated with cell differentiation. Solid cell nests of the thyroid are composed of main cells and $C$ cells, and the main cells have been suggested to be pluripotent cells, contributing to the histogenesis of $C$ cells and follicular cells. ${ }^{15}$ It was reported that Gal-3 along with p63 and Bcl-2 were positively stained in main cells of solid cell nests, ${ }^{16}$ which suggested that Gal-3 might be a marker of pluripotent main cells of thyroid. However, in the study of oropharynx and larynx squamous cancer, Gal-3 reactivity was not detected in the basal cell layer of normal epithelia, and tumor cells expressed Gal-3 with an intensity positively correlated with tumor differentiation. ${ }^{17}$ It seems that Gal-3 expression might be the marker for pluripotent cells or differentiated cells due to different cell types. Ellerhorst et al. ${ }^{18}$ reported that, in prostate tissues, the expression of Gal-3 in the luminal cells of normal prostate and prostatic intraepithelial neoplasia was heterogeneous but intense and uniform in the basal cells.

AR, a steroid hormone receptor member of the larger nuclear receptor superfamilies, ${ }^{19}$ plays an essential role in development and differentiation of the prostate and in development of prostate cancer. Structurally, AR has three areas: an amino-terminal area, which can independently stimulate transcription; a central DNA-binding domain; and a ligand-binding domain located in the carboxy terminal. ${ }^{19-21}$

\footnotetext{
${ }^{1}$ Department of Oncology, Karmanos Cancer Institute, Wayne State University, Detroit, MI, USA; ${ }^{2}$ Vattikuti Urology Institute, Henry Ford Hospital, Detroit, MI, USA and ${ }^{3}$ Microscopy, Imaging and Cytometry Resources Core, Karmanos Cancer Institute, Wayne State University, Detroit, MI, USA

${ }^{*}$ Corresponding author: Y Wang, Tumor Progression and Metastasis Program, Karmanos Cancer Institute, School of Medicine, Wayne State University, 110 East Warren Avenue, Detroit, Ml 48201, USA. Tel: + 1313578 4333; Fax: + 1313831 7518; E-mail: karmanos48201@gmail.com

or A Raz, Department of Oncology, Karmanos Cancer Institute, Wayne State University, 110 East Warren Avenue, Detroit, Ml 48201, USA. Tel: + 13135784330 ; Fax: + 1313831 7518; E-mail: raza@karmanos.org

${ }^{4}$ These authors contributed equally to this work.

Keywords: Gal-3; AR; prostate cancer; basal marker

Abbreviations: AR, androgen receptor; CARNs, castration-resistant NKx3.1-expressing cells; CK-18, cytokeratin-18; Gal-3, galectin-3; GST- $\pi$, glutathione $S$-transferase- $\pi$; MMP, matrix metallopeptidase; PSA, prostate-specific antigen; PTEN, phosphatase and tensin homolog

Received 23.4.13; revised 24.6.13; accepted 28.6.13; Edited by M Agostini
} 
In the absence of androgen, AR associates with a heat-shock protein 90 complex, which functions as a chaperone to maintain AR in a ligand-binding conformation. Upon androgen binding, AR undergoes a conformational change that results in formation of a homodimer, DNA binding, and recruitment of multiple transcription factors that activate the transcription of androgen-dependent genes. ${ }^{22}$ In general, AR expression has been reported to be extremely heterogeneous in prostate cancer specimens, reflecting the histological heterogeneity of the tumor. ${ }^{23} \mathrm{AR}$ is also considered as the characteristic marker for luminal phenotype of prostate epithelium. ${ }^{24-26}$

Our study found that the expression of Gal-3 was opposite to that of $A R$ in some prostate cancer cell lines. Based on the above information, we hypothesize that Gal-3 might be a biomolecular marker for basal cell phenotype in human prostate. The results of our study can be used in the diagnosis of subtypes of prostate cancer and guide appropriate personalized therapeutic strategies according to the expression profile of Gal-3 and AR.

\section{Results}

The opposite expressions of Gal-3 and AR in human prostate cancer cells. Endogenous Gal-3 and AR protein expressions were examined using western blot analysis in androgen-dependent cells $\mathrm{LNCaP}$ and androgen-independent cells DU145 and PC3. AR-expressing LNCaP cells have no endogenous expression of Gal-3; however, AR-non-expressing DU145 and PC3 cells have strong expression of Gal-3 (Figure 1a). To further investigate whether or not Gal-3 and AR regulate each other's protein expression, the expression of one of them was compared after another protein expression was modulated. As shown in Figure 1b, neither Gal-3 overexpression in LNCaP cells nor Gal-3 knockdown in PC3 cells changed the expression level of AR; similarly, AR overexpression in PC3 cells had no regulatory effect on Gal3 expression (Figure 1c).

Gal-3 as a new marker for basal cell characterization. As the expression of Gal-3 is opposite to that of $A R$ and $A R$ is well accepted as the marker for luminal phenotype in differentiation of human prostate cells, we assumed that Gal-3 expression might be associated with basal characteristics. Some basal cell markers such as GST- $\pi^{27}$ and Bcl- $2^{28}$ and luminal cell markers such as $\mathrm{CK}-18^{29}$ and $\mathrm{AR}^{24}$ were examined and compared together with Gal-3 in different prostate cancer cell lines. As shown in Figures $2 \mathrm{Aa}$ and $\mathrm{b}$, AR-expressing cells, such as LNCaP and C4-2B, had no detectable endogenous expression of Gal-3 and other basal markers; however, cells negative for AR, such as DU145, PC3, and VUI3, displayed strong expression levels of Gal-3, GST- $\pi$, and Bcl-2. In DU145 and VUI3 cells, CK-18 was still detectable but very weak, suggesting some intermediate characteristics of these cells. The similar expression profile was also detected in normal prostate epithelial cells PZ-HPV-7 (Figure 2B). Double staining of Gal-3 and AR was performed using immunohistochemistry in human prostate cancer tissues. Well-differentiated cancer tissues still displayed prostate gland structure, cells in the luminal layer
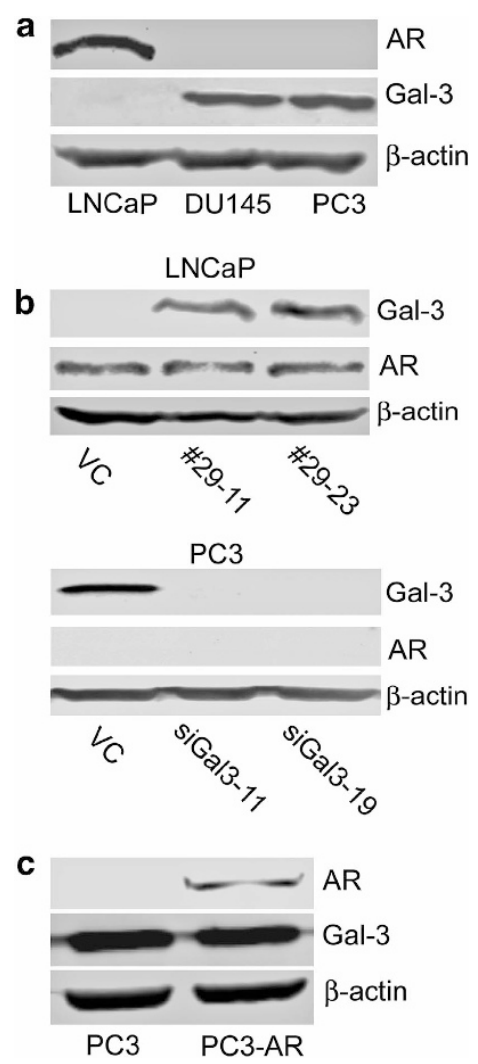

Figure 1 The expression pattern of Gal-3 and AR in human prostate cancer cells. The expression levels of related proteins were analyzed by western blot. (a) The expression of Gal-3 and AR in LNCaP, DU145, and PC3 cells. (b) Gal-3 modulation had no effect on endogenous AR level. VC, cells transfected with a nontarget control vector; no. 29-11 and no. 29-23, LNCaP clones with Gal-3 overexpression; siGal3-11 and siGal3-19, PC3 clones with Gal-3 knockdown. (c) AR overexpression had no effect on Gal-3 level in PC3 cells. PC3-AR, PC3 cells transfected with AR. $\beta$-Actin was used as the loading control. Data are representative of three independent experiments

with $\mathrm{AR}^{+}$(brownish-red color in nuclei), and Gal-3 ${ }^{+}$cells (bluish-gray color in nuclei and cytoplasm) localized in the basal layer (Figure 2Ca); in poorly differentiated cancer tissues, the normal structure was destroyed, and Gal-3 ${ }^{+}$ cells were scattered in $\mathrm{AR}^{+}$cells (Figure $2 \mathrm{Cb}$ ), and a positive reactivity to these two antigens was not detected together in the same cell. Both in vitro and vivo results indicate that Gal-3 can serve as a marker for basal phenotype.

Cells positive with basal cell markers are more aggressive. VUI3 cells were derived from LNCaP cells after continuous culture of $>90$ passages. Various cell biological behaviors were compared in LNCaP and C4-2B (luminal phenotype) and VUI3 cells (basal phenotype). For cell proliferation, VUI3 cells showed fastest cell growth rate; especially on day 5 after seeding, the number of VUI3 cells was much more than that of $\mathrm{LNCaP}$ or $\mathrm{C} 4-2 \mathrm{~B}$ cells (Figure $3 \mathrm{~A}$ ). In response to the chemotherapeutic drug cisplatin, both LNCaP and C4-2B cells showed strong activation of caspase-3; however, VUI3 cells showed only weak activation (Figure 3Ba). Similarly, annexin V/7aminoactinomycin $D(7-A A D)$ staining showed that cisplatin 
A a

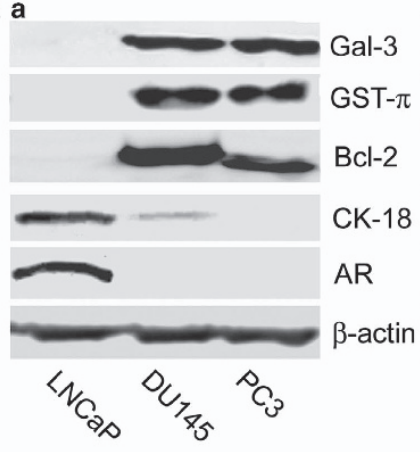

b
B

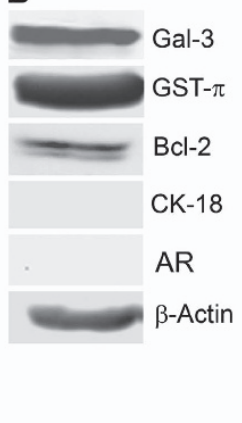

C
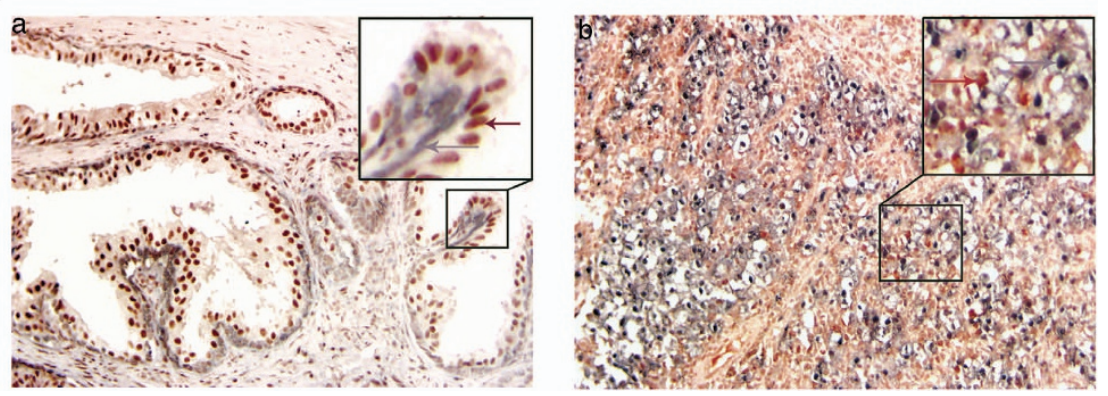

Figure 2 Gal-3 expression may serve as a new basal cell marker for human prostate cancer cells. The expression profile of basal and luminal markers in LNCaP, DU145, and PC3 cells (Aa); LNCaP, C4-2B, and VUI3 cells (Ab); and normal prostate epithelial cells PZ-HPV-7 (B). The expression pattern of Gal-3 is in accordance with markers for basal phenotype such as GST- $\pi$ and Bcl-2 but opposite with makers for luminal phenotype such as CK-18 and AR. $\beta$-Actin was used as the loading control. Data are representative of three independent experiments. (C) The pattern of opposite expressions of Gal-3 and AR in human prostate cancer tissues. Double staining of Gal-3 and AR in the same section was performed using immunohistochemistry. Gal-3-positive cells were negative for AR (arrows point to Gal-3, which is represented with bluish-gray staining in nucleus and cytoplasm), whereas AR-positive cells (arrows point to brownish-red color in nucleus) were negative for Gal-3. Line boxed pictures localized in the upper right corner of each picture represent $\times 400$ magnification of corresponding areas in $\times 200$ magnification pictures. (a) Gleason 2; (b) Gleason 5

treatment caused $15.9 \%$ apoptosis in $\mathrm{LNCaP}$ cells and $18.1 \%$ in C4-2B cells but only $6.5 \%$ in VUI3 cells (Figure 3Bb), which means VUI3 cells were resistant to cisplatin. Moreover, the antiapoptotic effect of VUI3 was reversed by downregulation of Gal-3 expression in VUI3 cells (Figure 3Bc), which suggests that Gal-3 expression is associated with antiapoptotic effect. The proliferation ability of one single cell in anchorage-dependent and anchorageindependent conditions was examined by colony formation assay in plates and soft agar, respectively. Compared with cells that were negative for basal cell markers, colonies formed from VUI3 cells were bigger and more abundant in both six-well plates (Figure 3C) and soft agar (Figure 3D), and the colony-forming efficiency of VUI3 cells was much higher than that of cells that lack basal markers. Metastatic potential of cells was examined by zymography and Matrigel cell invasion assay. Compared with $\mathrm{LNCaP}$ or C4-2B cells, VUI3 cells secreted much more active matrix metallopeptidase (MMP-2 and MMP-9), which are metastasis-related proteins $^{30,31}$ (Figure 3E), and more VUI3 cells invaded through Matrigel toward chemoattractant (Figure 3F), suggesting higher metastatic potential of VUI3 cells.

Clinical application of Gal-3 in diagnosis of subtypes of prostate cancer. Double staining of Gal-3 and AR in the same slide and single staining of p63 in another serial section slide were performed in human prostate cancer tissue arrays.
Among 40 cases of cancer tissues, 15 cases were $\mathrm{Gal}-3^{+} / \mathrm{AR}^{-}$ $(15 / 40)$ and 25 cases were $\mathrm{Gal}^{-} 3^{-} / \mathrm{AR}^{+}$(25/40). As shown in Figure 4, double-staining results demonstrated that cancer cells that were $\mathrm{Gal}-3^{+}$did not show AR-positive reactivity; in contrast, cells that were Gal-3- ${ }^{-}$showed ARpositive staining, which is in accordance with the expression pattern of Gal-3/AR in vitro. p63, another marker for stem cells or basal cells, ${ }^{32}$ was used here as the positive control. In 40 cancer tissues, 6 cases displayed p63-positive staining (6/40). $\mathrm{p} 63^{+}$areas were in accordance with $\mathrm{Gal}-3^{+}$areas, whereas ${\mathrm{p} 63^{-}}^{-}$areas were the same areas where cells showed Gal- $^{-} / \mathrm{AR}^{+}$(Figures $4 \mathrm{c}$ and d). Of note, some cases that were $\mathrm{Gal}-3^{+}$did not show p63-positive staining. The reason for this might be that p63 disappears before Gal-3 during the differentiation from basal to luminal phenotype; therefore, Gal-3 will be a valuable marker to distinguish basal-intermediate subtypes of cancer cells in clinical diagnosis.

\section{A therapeutic strategy targeting Gal-3 for prostate} cancer treatment. As we demonstrated above, Gal-3 could be used as a marker for basal cell phenotype, and cells with basal characteristics are more aggressive. We suggest that Gal-3 could be a therapeutic target for prostate cancer rich with basal characteristic cells. In our previous study, we knocked down Gal-3 expression in PC3 cells and then injected Gal-3-knockdown PC3 cells and control cells into nude mice. The tumors formed from Gal-3-knockdown cells 
A

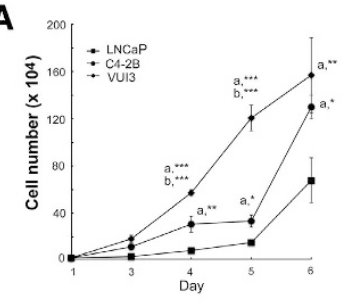

B a

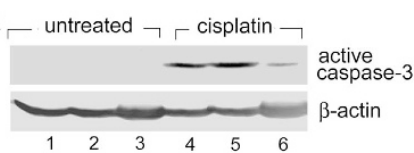

B b
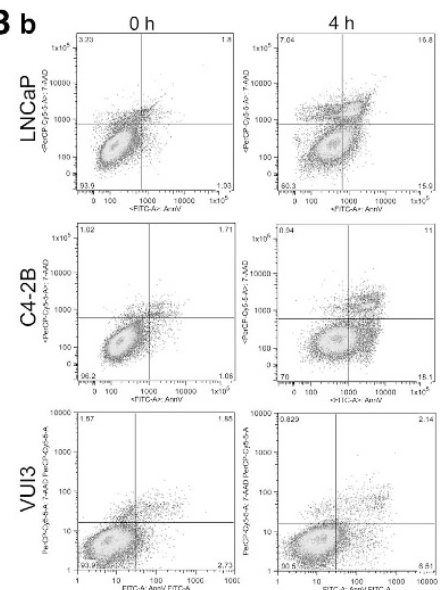

C

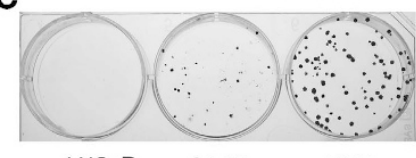

$\mathrm{NCaP}$

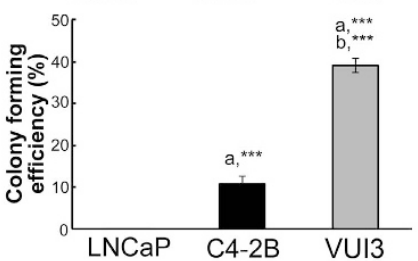

$\mathrm{Bc}$
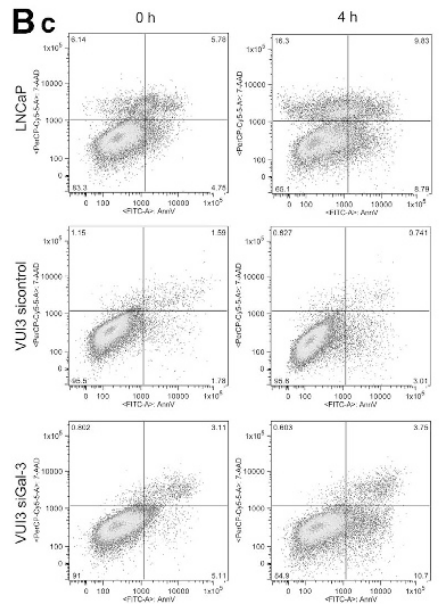

D
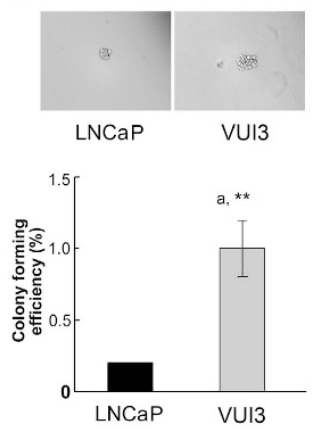

E

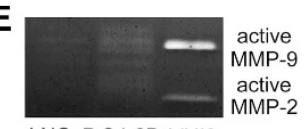

LNCaP C4-2B VUI3

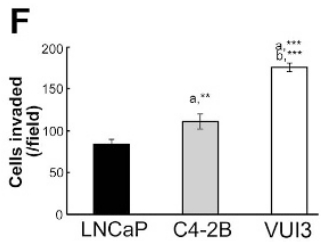

Figure 3 More aggressive phenotype of prostate cancer cells expressing basal cell markers. (A) VUI3 cells had a higher growth rate. The alive cell number was counted using automated cell counter. (B) VUI3 cells were resistant to the chemotherapeutic drug cisplatin, and the resistance was reversed by Gal-3 knockdown. (Ba) Cells were treated with $50 \mu \mathrm{M}$ cisplatin for $16 \mathrm{~h}$ and then subjected to western blot analysis of active caspase-3. $\beta$-Actin was used as the loading control. 1 and 4, LNCaP; 2 and $5, \mathrm{C} 4-2 \mathrm{~B}$; 3 and 6, VUI3. (Bb) FITC annexin V apoptosis detection. Cells were treated with $100 \mu \mathrm{M}$ cisplatin for $4 \mathrm{~h}$ and then stained with FITC annexin V/7-AAD and analyzed by flow cytometry. Early-apoptotic cells were shown in the lower right corner of the image. (Bc) Gal-3 knockdown increased the number of apoptotic VUI3 cells in response to cisplatin. VUI3 cells were transfected with Gal-3 siRNA or control siRNA as described in the Materials and methods section. Thirty-eight hours later, cells were treated with $100 \mu \mathrm{M}$ cisplatin for $4 \mathrm{~h}$, stained with FITC annexin V/7-AAD, and analyzed by flow cytometry. VUI3 cells showed higher colony formation rate in six-well plates (C) and soft agar (D). Upper panel, picture of colonies; lower panel, the graph of colony-forming efficiency. (E) Gelatin zymography assay showed more active MMP-2 and MMP-9 in VUI3 cells. (F) Chemoinvasion assay showed more VUI3 cells invaded through Matrigel. (a) C4-2B or VUI3 versus LNCaP; (b) VUI3 versus C4-2B. Error bars represent S.D.; * $P<0.05$, ${ }^{* *} P<0.01,{ }^{* * *} P<0.001$. Data are representative of three independent experiments

were smaller than those from control cells. ${ }^{33}$ The formed tumors were prepared and subjected to immunohistochemistry staining of apoptosis- and metastasis-related proteins. As shown in Figure 5, compared with tumors formed from control cells, those from Gal-3-knockdown cells showed stronger staining for proapoptotic protein caspase-3 and weaker staining for antiapoptotic protein $\mathrm{Bcl}-2$ and metastasis-related protein MMP-9, suggesting that downregulation of Gal-3 helps to increase the apoptosis of cancer cells and inhibit metastasis potential.

\section{Discussion}

Prostate cancer is the second leading cause of cancer death in men in Western countries. ${ }^{34}$ Normal prostate glands are composed of three main epithelial cells: basal, luminal, and neuroendocrine cells. Cellular origin of prostate cancer is still argued. Classically, prostate cancer is thought to originate from luminal cells, as most tumor cells express luminal characteristics. ${ }^{35}$ It has been shown that candidate luminal progenitor cells in the prostate tumor derived from a phosphatase and tensin homolog (PTEN)-knockout mouse can act as tumor-initiating cells. ${ }^{36}$ Studies of PSA-Cre; PTEN ${ }^{\text {flox/flox }}$ mice have suggested a rare luminal $\mathrm{Clu}^{+}$ Tacstd2 ${ }^{+}$Sca- $1^{+}$population as corresponding to the cells of origin in this model. ${ }^{4}$ Furthermore, a recent study has identified a rare luminal population of CARNs (castrationresistant NKX3.1-expressing cells) that can self-renew in vivo and reconstitute prostate ducts in the renal grafts. Moreover, deletion of PTEN in CARNs resulted in the formation of invasive carcinoma following androgen repletion and prostate regeneration. ${ }^{37}$

In contrast, other studies have demonstrated that basal cells could also serve as the cells of origin for prostate cancer. A basal cell of origin has been suggested by a study of $\mathrm{Pb}-\mathrm{Cre} 4 ; \mathrm{PTEN}^{\text {flox/flox }}$ mice, which display an expansion of basal cells as well as intermediate cells. ${ }^{7}$ Mouse Lin ${ }^{-}$Sca- $1^{+}$ CD49fhigh cells, a predominantly basal population, can differentiate into luminal cells in xenografts. ${ }^{38}$ Moreover, lentiviral overexpression of ERG1 and coactivation of the 

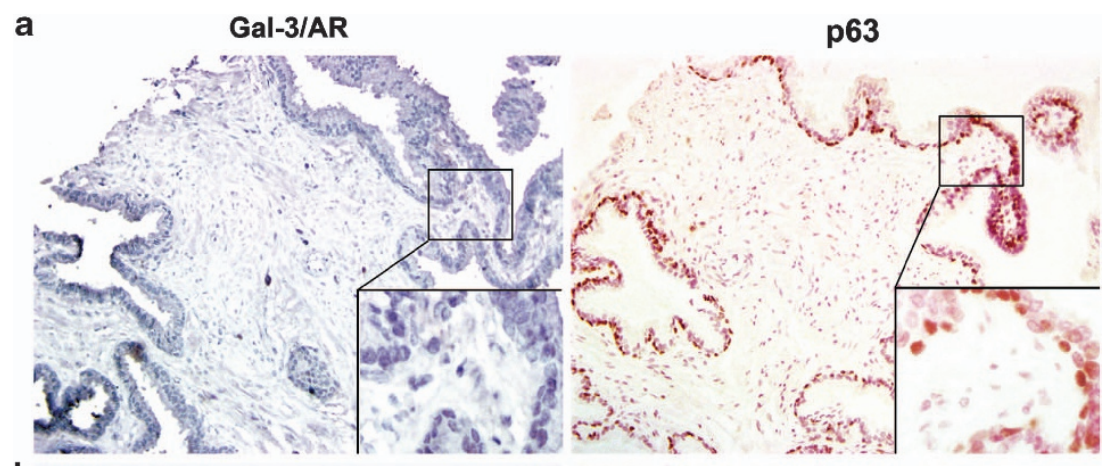

b

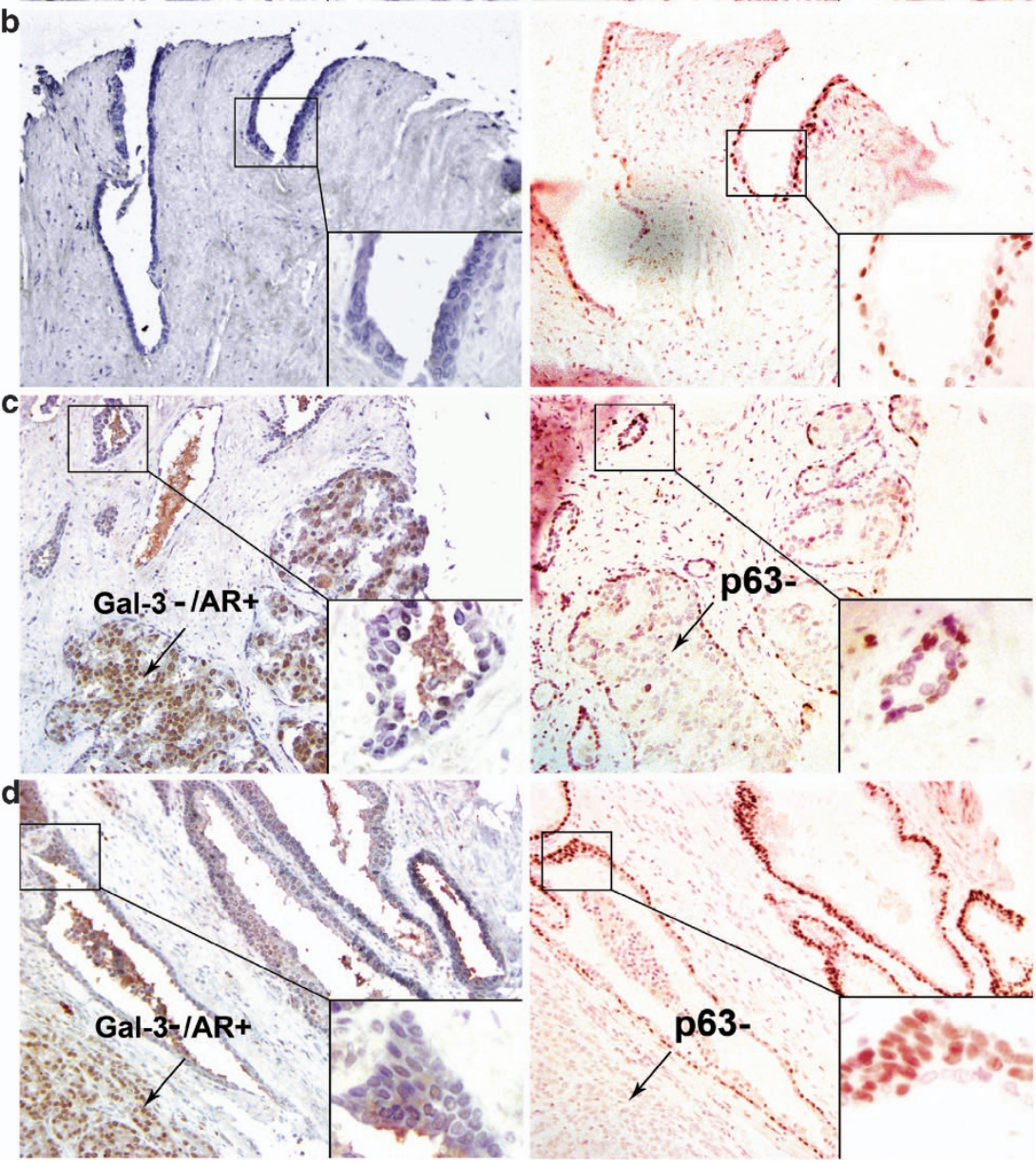

Figure 4 Confirmation of Gal-3 as a new basal marker in human prostate cancer tissue assays. Double staining of Gal-3/AR (left) and single staining of p63 (right) were performed by immunohistochemistry. Gal-3 positive, bluish gray in nucleus and cytoplasm; AR positive, brownish red in nucleus; p63 positive, red in nucleus. Gal-3-positive cells were negative for AR staining but were in accordance with p63-positive areas. Line boxed pictures localized in the lower right corner of each picture represent $\times 400$ magnification of corresponding areas in $\times 200$ magnification pictures. Arrows indicate Gal-3 ${ }^{-} / \mathrm{AR}^{+}$areas, which are also p63 ${ }^{-}$. (a) Normal; (b) Gleason 2; (c) Gleason 3; (d) Gleason 4

Akt and AR signaling pathway in Lin ${ }^{-}$Sca- $1^{+}$CD $49 f^{\text {high }}$ cells resulted in oncogenic transformation. ${ }^{8}$ Importantly, a recent study has shown that basal cells, but not the luminal cells, are the possible cells of origin for prostate cancer, and transformed basal cells can generate prostate cancers with luminal phenotypes. ${ }^{9}$

In addition, it was hypothesized that prostate cancer stem cells might be the cells of origin for prostate cancers. ${ }^{10,11}$ Many studies were performed to identify putative prostate cancer stem cells. In the case of mouse prostate cancer,
$\mathrm{Lin}^{-}$Sca- $1^{+} \mathrm{CD}_{49 f^{+}}$cells from Pb-Cre4;PTEN ${ }^{\text {floxflox }}$ mice have been shown to have tumor-initiating properties. ${ }^{39}$ In human prostate cancer, putative cancer stem cells have been isolated with a $\mathrm{CD}_{133^{+}} \alpha 2 \beta 1$ integrin ${ }^{\text {high }} \mathrm{CD} 44^{+}$cell-surface marker. ${ }^{40}$ Thus, based on the above evidence, we believe that prostate cancer can indeed arise from distinct cell types of origin and might result in different cancer subtypes.

Roles of Gal-3 in tumor progression have been well studied previously. It has been reported that the positive expression rate of Gal-3 decreases during the malignant transformation 


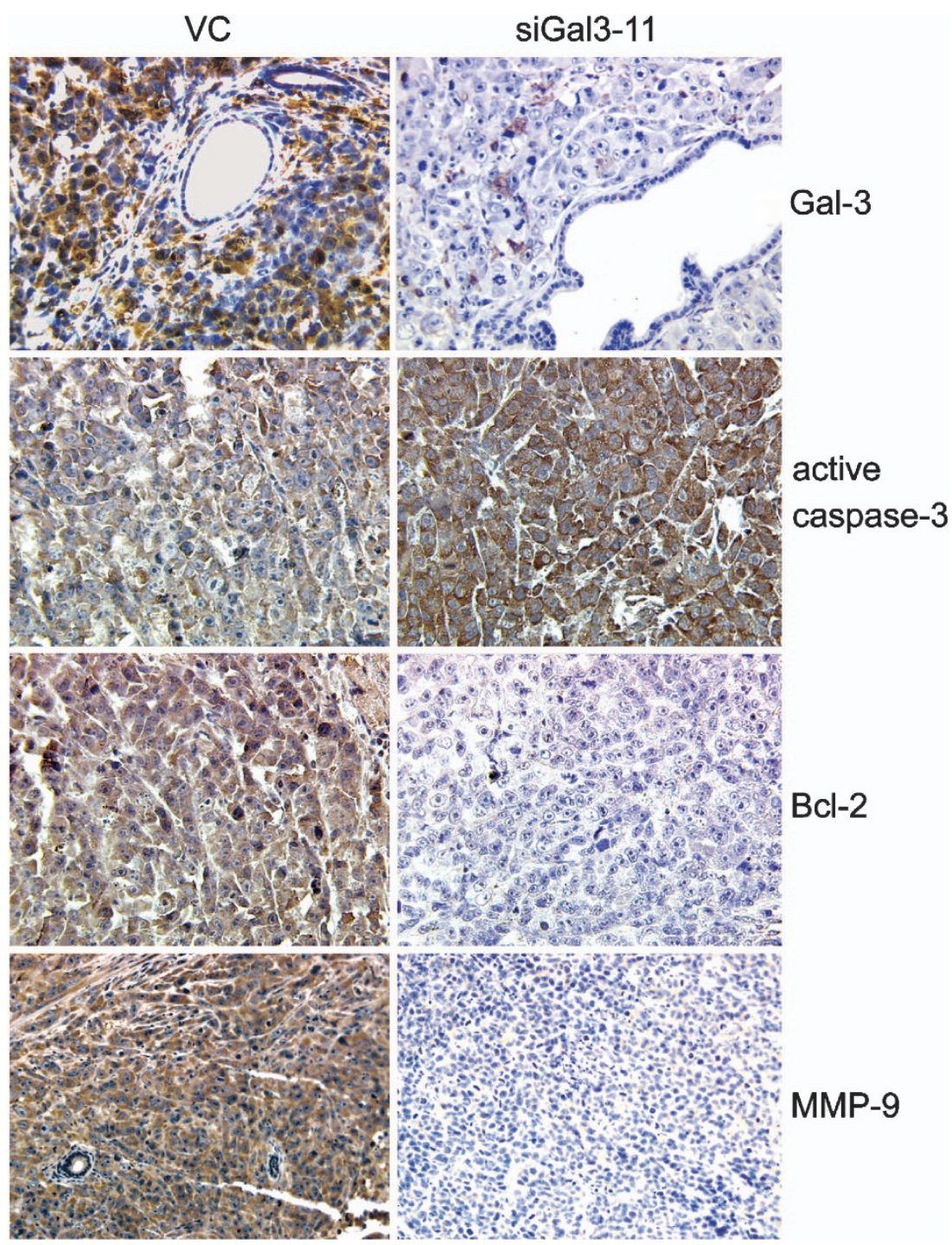

Figure 5 Downregulation of Gal-3 increased apoptotic potential and decreased metastasis potential of prostate cancer cells in a xenograft model. Appropriate cancer cells were injected into nude mice, and the tumor model was established as previously described. ${ }^{33}$ Tumors were sectioned and subjected to immunohistochemistry as described in the Materials and methods section. The positive staining for all related proteins was shown in brown color. VC, PC3 cells transfected with a non-target control vector; siGal3-11, PC3 clone with Gal-3 knockdown. Magnification, $\times 200$

of prostate epithelium. ${ }^{41,42}$ Here, we propose a new function of Gal-3 and its significance in prostate cancer. Experiments in our previous study showed that the positive staining of Gal-3 in the luminal layer of prostate epithelium was heterogeneous but uniform in the basal layer, consistent with reports of Ellerhorst et al., ${ }^{18}$ suggesting that the expression of Gal-3 might differentially reflect the heterogeneity of prostate cancer. AR, a nuclear hormone receptor, has been reported to play key roles in the development of normal prostate and cancer progression. During the progression of prostate cancer, various alterations of AR signaling have been identified including AR amplification, ${ }^{43}$ mutation, ${ }^{44}$ and activation by other signaling pathways. ${ }^{45}$ The expression of AR in prostate cancer tissues is also heterogeneous. Combined analysis of the expression profile of Gal-3 and AR will provide us more comprehensive information to understand the heterogeneity of prostate cancer.
In this study, we found that the expression of Gal-3 is always opposite to that of $A R$ in various prostate cancer cells, that is, the pattern of Gal-3 ${ }^{+} / \mathrm{AR}^{-}$or Gal- $3^{-} / \mathrm{AR}^{+}$. However, the reason for this pattern is not because Gal-3 or AR regulates each other's protein expression (Figures $1 \mathrm{~b}$ and $\mathrm{c}$ ). Besides the roles in cancers, Gal-3 has also been demonstrated to be associated with cell differentiation. Brand et al. ${ }^{46}$ reported that Gal-3 favored terminal differentiation of myeloid progenitors. The secretion of Gal-3 was also associated with the differentiation step of kidney intercalated cells. ${ }^{47}$ Based on the roles of Gal-3 in cell differentiation and its opposite expression to AR, we propose that Gal-3 might serve as a new marker for basal cell phenotype. We detected Gal-3 and various basal and luminal cell markers in different prostate cancer cell lines. Our results showed that the expression pattern of Gal-3 was always consistent with that of other basal cell markers and, however, opposite to that of luminal cell 
markers (Figures 2Aa and b). In the normal epithelial cell line PZ-HPV-7, we found that Gal-3, GST- $\pi$, and Bcl-2 were all positive, but $A R$ and $C K-18$ were negative, the same pattern as that in prostate cancer cells. Moreover, immunohistochemistry staining in prostate cancer tissues showed the localization of $\mathrm{Gal}-3^{+}$cells in the basal layer of prostate ducts (Figure $2 \mathrm{C}$ ), confirming the proposal of Gal-3 as a new basal cell marker.

Even though prostate cancer is predominantly luminal phenotype, it has been reported that most androgenindependent prostate cancers express basal cell characteristics. ${ }^{3}$ In addition, Liu et al. ${ }^{48}$ analyzed and sorted CD57 ${ }^{+}$ (a luminal cell marker) and CD44 ${ }^{+}$(a basal cell marker) cells from various prostate cancer tissues and found that CD57 ${ }^{+}$ cells predominated in primary cancer tissues; however, $\mathrm{CD}_{4}{ }^{+}$cells predominated in metastasis tissues. In our study, we found that compared with LNCaP or C4-2B cells, which are luminal phenotypes, LNCaP-derivative VUI3 cells, which express basal characteristics, display higher growth rate, resistance to chemotherapeutic drugs, elevated colony formation efficiency, and higher metastasis potential, suggesting that cancer cells with basal characteristics are more aggressive.

Liu et $a l^{48}$ also found that all the prostate tumor tissues were characterized by the ratio of $\mathrm{CD} 57^{+}$cells to $\mathrm{CD} 44^{+}$ cells. As prostate cancers express both luminal and basal characteristics and basal phenotype is more aggressive, it has important clinical significance to distinguish the subtypes of prostate cancers. Our results (Figure 4) in prostate cancer tissue array further confirmed the clinical value of Gal-3 as a new marker for basal cell phenotype. Double staining of Gal-3 and $A R$ could be a very useful method to distinguish cell subtypes of prostate cancers. Previous studies demonstrated that secreted Gal-3 was the substrate of MMPs. ${ }^{49}$ Compared with intact Gal-3, the cleaved Gal-3 leads to increased cell invasion of breast cancer cells and angiogenesis, which might explain how Gal-3 could promote a more aggressive phenotype of prostate cancers. Knapp et al. ${ }^{50}$ reported that Gal-3 expression in prostate cancer tissues significantly correlated with biochemical recurrence. Gal-3 expression was reported as a useful predictive factor for prognosis of bladder cancer. ${ }^{51}$ There is the possible correlation between Gal-3 expression and prostate cancer patient survival. The ratio of $\mathrm{Gal}^{-}{ }^{+}$cells to $\mathrm{AR}^{+}$cells could guide personalized therapy for prostate cancer patients and then improve the patient survival.

It has been demonstrated that inhibition of Gal-3 functions helps to suppress the progression of prostate cancer. Oral administration of modified citrus pectin, an inhibitor of Gal-3, significantly reduced lung metastasis of prostate cancer. ${ }^{52}$ Gal-3 knockdown in prostate cancer cells was associated with reduced cell proliferation, cell migration and invasion, colony formation in soft agar, and tumor formation in nude mice. ${ }^{33}$ In this study, our results showed that tumors formed by Gal-3knockdown prostate cancer cells exhibited stronger immunostaining of caspase-3 and weaker staining of Bcl-2 and MMP-9, suggesting that downregulation of Gal-3 helps to suppress the progression of prostate cancer. All the above findings indicate that in the case of high ratio of $\mathrm{Gal}-3^{+}$to $\mathrm{AR}^{+}$cells of prostate cancer, therapies targeting Gal-3 inhibition could be considered to favor the treatments for advanced prostate cancers.

Our study demonstrates that Gal-3 may serve as a new marker for basal characteristics in prostate cancer. Our findings build the bridge between laboratory research and clinical applications. Double staining of Gal-3 and AR will help to analyze the cell components of prostate cancer tissues and then determine the main subtype of prostate cancer. The ratio of $\mathrm{Gal}^{+} 3^{+}$to $\mathrm{AR}^{+}$cells in patient tissues will serve as a valuable guide for personalized treatment to achieve better treatment efficacy.

\section{Materials and Methods}

Antibodies. Monoclonal rat anti-Gal-3 antibody $M 3 / 38$ was isolated from hybridoma supernatant of TIB-166 (American Type Culture Collection, Manassas, VA, USA); mouse anti-AR and rabbit anti-Bcl-2 were purchased from Cell Signaling Technology (Danvers, MA, USA); mouse anti-GST- $\pi$, rabbit anti-active caspase-3, and mouse anti-MMP-9 were purchased from BD Biosciences (San Jose, CA, USA); mouse anti-p63 was from Abcam (Cambridge, MA, USA); anti-CK-18 was from Dako (Carpinteria, CA, USA); cisplatin and mouse anti- $\beta$ actin were purchased from Sigma Chemicals (St. Louis, MO, USA).

Cell culture. Human prostate cancer cells LNCaP (ATCC no. CRL-1740), DU145 (ATCC no. HTB-81), PC3 (ATCC no. CRL-1435), and normal prostate epithelial cells PZ-HPV-7 (ATCC no. CRL-2221) were purchased from American Type Culture Collection. LNCaP-derivative C4-2B cells were purchased from Urocor Labs (Oklahoma City, OK, USA). These cell lines have been tested and authenticated by the supplier. Gal-3-overexpressing LNCaP clones, nos. 29-11 and 29-23, and the non-target control vector clone VC were kindly provided by Dr. Reuben Lotan (University of Texas MD Anderson Cancer Center, Houston, TX, USA). Gal-3-knockdown PC3 clones, siGal3-11 and siGal3-19, and the non-target control vector clone VC were established as described in our previous study. ${ }^{33}$ PC3 cells transfected with AR and LNCaP-derivative VUI3 cells were kindly provided by Dr. Prem Veer Reddy. Parental LNCaP, DU145, PC3, C4-2B, and VUI3 cells were cultured in RPMI-1640 medium supplemented with $10 \%$ fetal bovine serum (FBS). PZ-HPV-7 cells were cultured in a keratinocyte serum-free medium with $0.05 \mathrm{mg} / \mathrm{ml}$ bovine pituitary extract and $5 \mathrm{ng} / \mathrm{ml}$ human recombinant epidermal growth factor. To maintain clones, $200 \mathrm{~g} / \mathrm{ml}$ G418 (Invitrogen, Grand Island, NY, USA) for LNCaP and PC3 transfectants were added to the culture media.

Western blot analysis. Cells were lysed in RIPA buffer containing protease inhibitors (Roche Applied Science, Nutley, NJ, USA). Western blot was performed as previously described. ${ }^{33}$

Cell growth assay. Cells were seeded at $2 \times 10^{4}$ cells per well into 24 -well plates. After seeding, starting from the third day until the sixth day, everyday cells were digested, stained with Trypan blue dye, and counted with a TC10 automated cell counter (Bio-Rad, Hercules, CA, USA).

Annexin V apoptosis detection. Cells were treated with $100 \mu \mathrm{M}$ cisplatin for $4 \mathrm{~h}$. After treatment, cells were stained by FITC annexin V apoptosis detection kit II (BD Biosciences) according to the manufacturer's instruction. Briefly, cells were washed twice with cold PBS and then resuspended in $1 \times$ binding buffer (0.01 M HEPES/ $\mathrm{NaOH}(\mathrm{pH} 7.4), 0.14 \mathrm{M} \mathrm{NaCl}, 2.5 \mathrm{mM} \mathrm{CaCl}_{2}$ ) at a concentration of $1 \times 10^{6} \mathrm{celll} / \mathrm{ml}$. A portion of $100 \mu \mathrm{l}$ of the solution $\left(1 \times 10^{5} \mathrm{cells}\right)$ was transferred to a 5 -ml culture tube, and $5 \mu \mathrm{l}$ of FITC annexin V and $5 \mu \mathrm{l}$ of 7-AAD were added. Cells were gently vortexed and incubated for $15 \mathrm{~min}$ at room temperature (RT) in the dark. A portion of $400 \mu \mathrm{l}$ of $1 \times$ binding buffer was added to each tube, and cells were analyzed by flow cytometry within $1 \mathrm{~h}$. Flow cytometry was performed at the Microscopy, Imaging and Cytometry Resources Core at Wayne State University.

siRNA transfection. Gal-3 siRNA and control siRNA (Santa Cruz Biotechnology, Santa Cruz, CA, USA) were reversely transfected into VUI3 cells using Lipofectamine RNAiMax reagent (Invitrogen) according to the manufacturer's instruction. 
Colony formation assay in plates. Cells were seeded at the density of 200 cells per well into six-well plates and cultured for 12 days. When colonies were visible, cells were fixed and stained with $0.1 \%$ crystal violet in $10 \%$ ethanol for $30 \mathrm{~min}$. The number of colonies, defined as $>50$ cells per colony, was counted, and colony formation efficiency was calculated as the ratio of the number of colonies to total seeded cells.

Anchorage-independent growth assay. Dishes $(60 \mathrm{~mm})$ were coated with $1 \%$ SeaPlaque agarose (BioWhittaker Molecular Applications, Rockland, ME, USA) dissolved in DMEM/10\% FBS. A total of 2000 cells suspended in DMEM/ $10 \%$ FBS containing $0.5 \%$ agarose were overlaid on the bottom layer. The plates were kept at $4{ }^{\circ} \mathrm{C}$ for $2 \mathrm{~h}$ and then moved to a tissue culture incubator. Twenty-four hours later, fresh DMEM/10\% FBS was placed on top and replaced every 3 days. Colonies were counted 3 weeks later and photographed using phase-contrast photomicrography. Colonies measuring $\geq 0.1 \mathrm{~mm}$ in diameter were scored. Colony formation efficiency was calculated as the ratio of the number of colonies to total seeded cells.

Gelatin zymography. Conditioned media were concentrated using Amicon Ultra centrifugal filter devices (EMD Millipore, Billerica, MA, USA), and protein concentration was determined using Bio-Rad protein assay reagent. Gelatin zymography was performed as previously described. ${ }^{33}$

Cell invasion assay. Cell invasion assay was performed using the Matrigel invasion chamber (BD Biosciences). Briefly, basic DMEM containing chemoattractant $(0.05 \mathrm{mg} / \mathrm{ml}$ laminin) was added to the chambers, and cells suspended in basic DMEM were seeded into the inserts. After $17 \mathrm{~h}$ of incubation, non-invading cells on the upper side of the inserts were removed using a cotton swab, and invading cells on the bottom side of the inserts were fixed and stained with the Diff-Quik stain set (Fisher Scientific, Pittsburgh, PA, USA). Quantification was performed by counting the stained cells under a microscope.

Immunohistochemistry. Prostate cancer tissue array serial sections (PR483a) including normal prostate tissues $(n=8)$ and malignant tumors $(n=40)$ were purchased from US Biomax (Rockville, MD, USA). Mouse prostate cancer model was established as described in our previous study, ${ }^{33}$ and the formed tumors were collected and prepared as usual. Sections were deparaffinized, rehydrated, and boiled in $1 \mathrm{mM}$ EDTA ( $\mathrm{pH}$ 8.0) by microwave for $15 \mathrm{~min}$. Endogenous peroxidase activity was blocked by $3 \% \mathrm{H}_{2} \mathrm{O}_{2}$, and nonspecific binding of immunoglobulin was minimized by blocking with Super Block (Scytek Laboratories, Logan, UT, USA) for $1 \mathrm{~h}$ at RT. For Gal-3 and AR double staining, sections were incubated with mouse anti-AR $(1: 50)$ overnight at $4{ }^{\circ} \mathrm{C}$, then linked with biotinylated anti-mouse (1:500; Vector Laboratories, Burlingame, CA, USA) for $30 \mathrm{~min}$ and the avidin-biotin-peroxidase complex for $30 \mathrm{~min}$ at RT, and colorized by Nova Red peroxidase substrate kit (Vector Laboratories). The same sections were then incubated with rat anti-Gal-3 $(1: 50)$ for $1 \mathrm{~h}$ at RT, linked with biotinylated anti-rat (1:500; Vector Laboratories) for $30 \mathrm{~min}$ and the avidin-biotinperoxidase complex for $30 \mathrm{~min}$, and colorized by $3,3^{\prime}$-diaminobenzidine tetrahydrochloride hydrate (Sigma Chemicals). For single-antigen staining, sections were incubated with appropriate primary antibodies overnight at $4{ }^{\circ} \mathrm{C}$ and appropriate biotinylated secondary antibodies and substrates (Nova Red peroxidase substrate kit for p63; 3,3'-diaminobenzidine tetrahydrochloride for Gal-3, caspase-3, Bcl-2, and MMP-9) at RT. Visualization and documentation were accomplished with an Olympus (Melville, NY, USA) BX40 microscope supporting a Sony (Tokyo, Japan) DXC-979MD 3CCCD video camera. Two investigators evaluated results in blinded manner. Sections with more than $10 \%$ of positive cancer cells were regarded as positive samples.

Statistical analysis. Data were expressed as mean \pm S.D. of three independent experiments and analyzed by a one-way ANOVA test using SPSS 14.0 software (SPSS Inc., Chicago, IL, USA). $P<0.05$ was considered statistically significant.

\section{Conflict of Interest}

The authors declare no conflict of interest.
Acknowledgements. We thank Dr. Reuben Lotan for providing Gal-3transfected LNCaP clones, Dr. Pratima Nangia-Makker for technical support, and Victor Hogan for revising the paper and figure preparation. This study was supported by the National Institutes of Health (NIH) grant R37CA46120-19 (to Avraham Raz) and the American Cancer Society grant 11-053-01-IRG (to Vitaly Balan). The Microscopy, Imaging and Cytometry Resources Core is supported, in part, by NIH Center grant P30CA022453 to the Karmanos Cancer Institute, Wayne State University, and the Perinatology Research Branch of the National Institutes of Child Health and Development, Wayne State University.

1. Jemal A, Siegel R, Ward E, Hao Y, Xu J, Thun MJ. Cancer statistics, 2009. CA Cancer J Clin 2009; 59: 225-249.

2. Wang G, Wang Z, Sarkar FH, Wei W. Targeting prostate cancer stem cells for cancer therapy. Discov Med 2012; 13: 135-142.

3. Long RM, Morrissey C, Fitzpatrick JM, Watson RW. Prostate epithelial cell differentiation and its relevance to the understanding of prostate cancer therapies. Clin Sci (Lond) 2005; 108: 1-11.

4. Korsten H, Ziel-van der Made A, Ma X, van der Kwast T, Trapman J. Accumulating progenitor cells in the luminal epithelial cell layer are candidate tumor initiating cells in a Pten knockout mouse prostate cancer model. PLoS One 2009; 4: e5662.

5. Iwata T, Schultz D, Hicks J, Hubbard GK, Mutton LN, Lotan TL et al. MYC overexpression induces prostatic intraepithelial neoplasia and loss of Nkx3.1 in mouse luminal epithelial cells. PLOS One 2010; 5: e9427.

6. Gurel B, Iwata T, Koh CM, Jenkins RB, Lan F, Van Dang C et al. Nuclear MYC protein overexpression is an early alteration in human prostate carcinogenesis. Mod Pathol 2008; 21: $1156-1167$

7. Wang S, Garcia AJ, Wu M, Lawson DA, Witte ON, Wu H. Pten deletion leads to the expansion of a prostatic stem/progenitor cell subpopulation and tumor initiation. Proc Natl Acad Sci USA 2006; 103: 1480-1485.

8. Lawson DA, Zong Y, Memarzadeh S, Xin L, Huang J, Witte ON. Basal epithelial stem cells are efficient targets for prostate cancer initiation. Proc Natl Acad Sci USA 2010; 107: 2610-2615.

9. Goldstein AS, Huang J, Guo C, Garraway IP, Witte ON. Identification of a cell of origin for human prostate cancer. Science 2010; 329: 568-571.

10. Maitland NJ, Frame FM, Polson ES, Lewis JL, Collins AT. Prostate cancer stem cells: do they have a basal or luminal phenotype? Horm Cancer 2011; 2: 47-61.

11. Oldridge EE, Pellacani D, Collins AT, Maitland NJ. Prostate cancer stem cells: are they androgen-responsive? Mol Cell Endocrinol 2011; 360: 14-24.

12. Inohara H, Akahani S, Raz A. Galectin-3 stimulates cell proliferation. Exp Cell Res 1998; 245: 294-302.

13. O'Driscoll L, Linehan R, Liang YH, Joyce H, Oglesby I, Clynes M. Galectin-3 expression alters adhesion, motility and invasion in a lung cell line (DLKP), in vitro. Anticancer Res 2002; 22: 3117-3125.

14. Nangia-Makker P, Nakahara S, Hogan V, Raz A. Galectin-3 in apoptosis, a novel therapeutic target. J Bioenerg Biomembr 2007; 39: 79-84.

15. Cameselle-Teijeiro J, Febles-Perez C, Sobrinho-Simoes M. Papillary and mucoepidermoid carcinoma of the thyroid with anaplastic transformation: a case report with histologic and immunohistochemical findings that support a provocative histogenetic hypothesis. Pathol Res Pract 1995; 191: 1214-1221.

16. Rios Moreno MJ, Galera-Ruiz H, De Miguel M, Lopez MI, Illanes M, Galera-Davidson H. Inmunohistochemical profile of solid cell nest of thyroid gland. Endocr Pathol 2011; 22: 35-39.

17. Plzak J, Smetana K Jr., Hrdlickova E, Kodet R, Holikova Z, Liu FT et al. Expression of galectin-3-reactive ligands in squamous cancer and normal epithelial cells as a marker of differentiation. Int $J$ Oncol 2001; 19: 59-64.

18. Ellerhorst J, Troncoso P, Xu XC, Lee J, Lotan R. Galectin-1 and galectin-3 expression in human prostate tissue and prostate cancer. Urol Res 1999; 27: 362-367.

19. Mangelsdorf DJ, Thummel C, Beato M, Herrlich P, Schutz G, Umesono K et al. The nuclear receptor superfamily: the second decade. Cell 1995; 83: 835-839.

20. Quigley CA, De Bellis A, Marschke KB, el-Awady MK, Wilson EM, French FS. Androgen receptor defects: historical, clinical, and molecular perspectives. Endocr Rev 1995; 16 : 271-321.

21. Brinkmann AO, Blok LJ, de Ruiter PE, Doesburg P, Steketee $K$, Berrevoets $C A$ et al. Mechanisms of androgen receptor activation and function. J Steroid Biochem Mol Biol 1999; 69: 307-313.

22. Balk SP. Androgen receptor as a target in androgen-independent prostate cancer. Urology 2002; 60(3 Suppl 1): 132-138; Discussion 138-139.

23. Tamburrino L, Salvianti F, Marchiani S, Pinzani P, Nesi G, Serni S et al. Androgen receptor (AR) expression in prostate cancer and progression of the tumor: lessons from cell lines, animal models and human specimens. Steroids 2012; 77: 996-1001.

24. Prins GS, Birch L, Greene GL. Androgen receptor localization in different cell types of the adult rat prostate. Endocrinology 1991; 129: 3187-3199.

25. Lipschutz JH, Foster BA, Cunha GR. Differentiation of rat neonatal ventral prostates grown in a serum-free organ culture system. Prostate 1997; 32: 35-42. 
26. Robinson EJ, Neal DE, Collins AT. Basal cells are progenitors of luminal cells in primary cultures of differentiating human prostatic epithelium. Prostate 1998; 37: 149-160.

27. Cookson MS, Reuter VE, Linkov I, Fair WR. Glutathione S-transferase PI (GST-pi) class expression by immunohistochemistry in benign and malignant prostate tissue. J Urol 1997; 157: 673-676.

28. Colombel M, Symmans F, Gil S, O'Toole KM, Chopin D, Benson M et al. Detection of the apoptosis-suppressing oncoprotein bc1-2 in hormone-refractory human prostate cancers. Am J Pathol 1993; 143: 390-400.

29. Liu AY, True LD, LaTray L, Nelson PS, Ellis WJ, Vessella RL et al. Cell-cell interaction in prostate gene regulation and cytodifferentiation. Proc Natl Acad Sci USA 1997; 94: 10705-10710.

30. Hendrix MJ, Seftor EA, Grogan TM, Seftor RE, Hersh EM, Boyse EA et al. Expression of type IV collagenase correlates with the invasion of human lymphoblastoid cell lines and pathogenesis in SCID mice. Mol Cell Probes 1992; 6: 59-65.

31. Sreenath T, Matrisian LM, Stetler-Stevenson W, Gattoni-Celli S, Pozzatti RO. Expression of matrix metalloproteinase genes in transformed rat cell lines of high and low metastatic potential. Cancer Res 1992; 52: 4942-4947.

32. Signoretti S, Waltregny D, Dilks J, Isaac B, Lin D, Garraway L et al. p63 is a prostate basal cell marker and is required for prostate development. Am J Pathol 2000; 157: 1769-1775

33. Wang Y, Nangia-Makker P, Tait L, Balan V, Hogan V, Pienta KJ et al. Regulation of prostate cancer progression by galectin-3. Am J Pathol 2009; 174: 1515-1523.

34. Corona G, Baldi E, Maggi M. Androgen regulation of prostate cancer: where are we now? J Endocrinol Invest 2011; 34: 232-243.

35. Sherwood ER, Berg LA, Mitchell NJ, McNeal JE, Kozlowski JM, Lee C. Differential cytokeratin expression in normal, hyperplastic and malignant epithelial cells from human prostate. J Urol 1990; 143: 167-171.

36. Ma X, Ziel-van der Made AC, Autar B, van der Korput HA, Vermeij M, van Duijn P et al. Targeted biallelic inactivation of Pten in the mouse prostate leads to prostate cancer accompanied by increased epithelial cell proliferation but not by reduced apoptosis. Cancer Res 2005; 65: 5730-5739.

37. Wang X, Kruithof-de Julio M, Economides KD, Walker D, Yu H, Halili MV et al. A luminal epithelial stem cell that is a cell of origin for prostate cancer. Nature 2009; 461: 495-500.

38. Lawson DA, Xin L, Lukacs RU, Cheng D, Witte ON. Isolation and functional characterization of murine prostate stem cells. Proc Natl Acad Sci USA 2007; 104: 181-186.

39. Mulholland DJ, Xin L, Morim A, Lawson D, Witte O, Wu H. Lin ${ }^{-}$Sca- $1^{+}$CD $49 f^{\text {high }}$ stem/ progenitors are tumor-initiating cells in the Pten-null prostate cancer model. Cancer Res 2009; 69: 8555-8562.

40. Collins AT, Berry PA, Hyde C, Stower MJ, Maitland NJ. Prospective identification of tumorigenic prostate cancer stem cells. Cancer Res 2005; 65: 10946-10951.
41. Pacis RA, Pilat MJ, Pienta KJ, Wojno K, Raz A, Hogan V et al. Decreased galectin-3 expression in prostate cancer. Prostate 2000; 44: 118-123.

42. Merseburger AS, Kramer MW, Hennenlotter J, Simon P, Knapp J, Hartmann JT et al. Involvement of decreased galectin-3 expression in the pathogenesis and progression of prostate cancer. Prostate 2008; 68: 72-77.

43. Visakorpi $T$, Hyytinen $E$, Koivisto $P$, Tanner M, Keinanen $R$, Palmberg $C$ et al. In vivo amplification of the androgen receptor gene and progression of human prostate cancer. Nat Genet 1995; 9: 401-406.

44. Taplin ME, Bubley GJ, Shuster TD, Frantz ME, Spooner AE, Ogata GK et al. Mutation of the androgen-receptor gene in metastatic androgen-independent prostate cancer. $N E n g / J$ Med 1995; 332: 1393-1398.

45. Nazareth LV, Weigel NL. Activation of the human androgen receptor through a protein kinase A signaling pathway. J Biol Chem 1996; 271: 19900-19907.

46. Brand C, Oliveira FL, Ricon L, Fermino ML, Boldrini LC, Hsu DK et al. The bone marrow compartment is modified in the absence of galectin-3. Cell Tissue Res 2011; 346: 427-437.

47. Al-Awqati $Q$. Terminal differentiation in epithelia: the role of integrins in hensin polymerization. Annu Rev Physiol 2010; 73: 401-412.

48. Liu AY, True LD, LaTray L, Ellis WJ, Vessella RL, Lange PH et al. Analysis and sorting of prostate cancer cell types by flow cytometry. Prostate 1999; 40: 192-199.

49. Nangia-Makker P, Wang Y, Raz T, Tait L, Balan V, Hogan V et al. Cleavage of galectin-3 by matrix metalloproteases induces angiogenesis in breast cancer. Int J Cancer 2010; 127: 2530-2541.

50. Knapp JS, Lokeshwar SD, Vogel U, Hennenlotter J, Schwentner C, Kramer MW et al. Galectin-3 expression in prostate cancer and benign prostate tissues: correlation with biochemical recurrence. World J Urol 2013; 31: 351-358.

51. Rodriguez Faba O, Palou J. Predictive factors for recurrence progression and cancer specific survival in high-risk bladder cancer. Curr Opin Urol 2012; 22: 415-420.

52. Pienta KJ, Naik H, Akhtar A, Yamazaki K, Replogle TS, Lehr J et al. Inhibition of spontaneous metastasis in a rat prostate cancer model by oral administration of modified citrus pectin. J Natl Cancer Inst 1995; 87: 348-353.

(c) (i) (2)(2) Cell Death and Disease is an open-access journal By ${ }^{2}$ sa published by Nature Publishing Group. This work is licensed under a Creative Commons Attribution-NonCommercialShareAlike 3.0 Unported License. To view a copy of this license, visit http://creativecommons.org/licenses/by-nc-sa/3.0/ 